\title{
Clinical Reasoning: A 24-year-old man with head tremor and decreased ceruloplasmin level
}

Junyu Lin, MD, Bi Zhao, MD, Bei Cao, MD, Xiaoqin Yuan, MD, Xiaojing Gu, MD, and Huifang Shang, MD

Neurology ${ }^{\circledR}$ 2020;95:e1906-e1910. doi:10.1212/WNL.0000000000010458

\section{Section 1}

A 25-year-old Chinese man had developed involuntary and irregular head tremor with no triggers at the age of 18 years. The head tremor occurred intermittently at first with a frequency of several times per week lasting from several minutes to up to an hour. His head tremor worsened progressively and became persistent at age 24 years. It was aggravated by exercise and emotional stress, relieved by relaxation and alcohol, and disappeared during sleep. He denied a family history of tremor. An initial diagnosis of essential tremor was made and he was referred to our department. Neurologic examination revealed mild cerebellar dysarthria, diffuse hyperreflexia, a "no-no" head tremor, and mild torticollis. The amplitude of the patient's head tremor was increased when he turned his head leftward and decreased when he turned rightward (video). Dysdiadochokinesia and minimally impaired tandem walking were also observed. Other neurologic examination findings included absence of gaze-evoked nystagmus, normal eye movements (saccades and smooth pursuit), and normal finger-nose and heel-to-shin tests.

\section{Questions for consideration:}

1. How would you categorize the tremor in this patient?

2. What further testing should be performed?
Correspondence

Dr. Shang

hfshang2002@126.com

GO TO SECTION 2

From the Department of Neurology, Rare Disease Center, West China Hospital, Sichuan University, Chengdu, Sichuan Province, China.

Go to Neurology.org/N for full disclosures. Funding information and disclosures deemed relevant by the authors, if any, are provided at the end of the article. 


\section{Section 2}

Head shaking without ataxia or torticollis was present at the initial presentation. The patient subsequently developed focal, action-type tremor that was irregular both in amplitude and rhythm and persisted in the supine position. The tremor was exacerbated by head turn away from dystonic posturing of the neck, and abated by head turn toward the dystonic neck posture (e.g., null point). The above features suggested the head tremor to be a dystonic tremor. Neurologic examination disclosed mild ataxia. For these reasons, a diagnosis of dystonia-ataxia syndrome was considered. The spectrum of genes associated with dystonia-ataxia syndrome are currently expanding with the development of next-generation sequencing ${ }^{1}$; more than 100 genetic disorders can present with dystonia-ataxia syndrome, including hereditary ataxias such as spinocerebellar ataxias (SCAs) and autosomal recessive ataxias, neurodegeneration with brain iron accumulation such as aceruloplasminemia, Wilson disease (WD), and others.

Of these diseases, WD is treatable and should be considered and evaluated, especially in cases of juvenile onset. We therefore performed ceruloplasmin level and found it to be moderately reduced (126 mg/L; normal $210-530 \mathrm{mg} / \mathrm{L}$ ). Levels of serum copper, urine copper, and serum ferritin were normal.

Ophthalmologic examination did not demonstrate KayserFleischer rings or retinal degeneration. Brain MRI showed mild atrophy of the cerebellum (figure, A). The prominent juvenile-onset extrapyramidal signs and decreased ceruloplasmin was suggestive of a diagnosis of $\mathrm{WD}$, while the normal urinary copper and absence of Kayser-Fleischer rings were not. To further exclude the diagnosis of WD, we screened the $A T P 7 B$ gene and detected no mutation. Since ceruloplasmin is encoded by the $C P$ gene, we performed a genetic analysis of $C P$, which elucidated a heterozygous mutation (c.2158C > T, p. Arg720Trp) (figure, D). Pedigree analysis revealed that the patient's 62-year-old father carried the same heterozygous mutation in $C P$ (figure, D). His mother had died of cancer.

\section{Questions for consideration:}

1. Can the heterozygous mutation of $C P$ account for the patient's symptoms?

2. What additional information would help you to decide the pathogenicity of the mutation?

Figure MRI and electropherogram

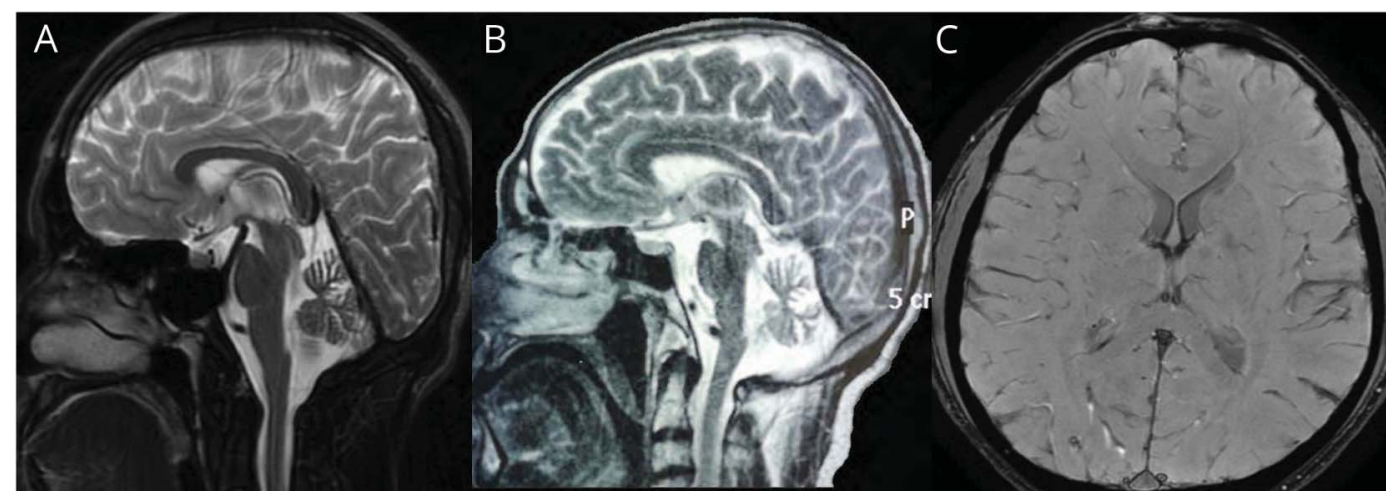

D

$\mathrm{E}$

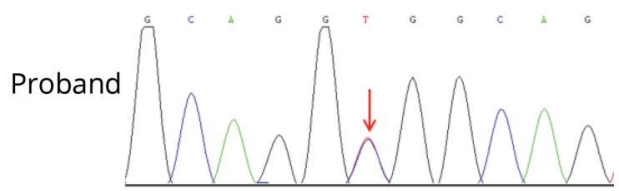

Proband
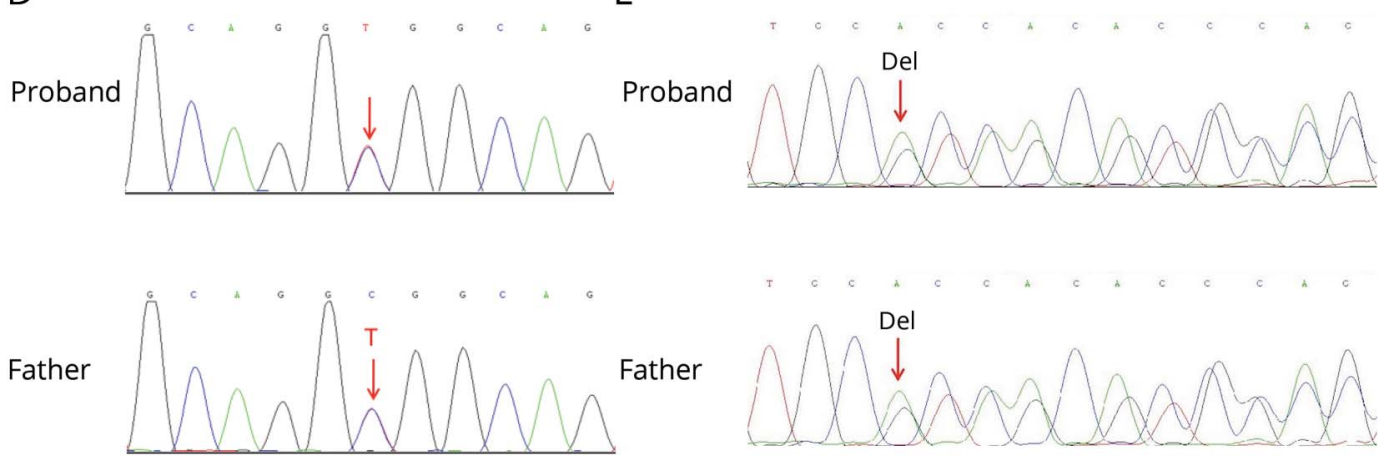

Father

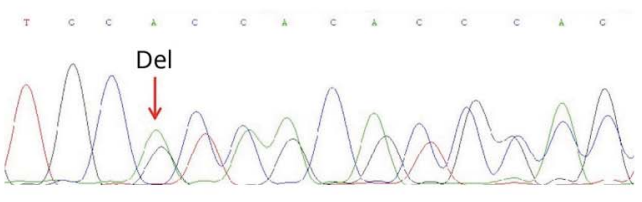

(A) Sagittal T2-weighted MRI of the proband showing mild cerebellar atrophy. (B) Sagittal T2-weighted MRI of the proband's father showing moderate cerebellar atrophy. (C) Axial susceptibility-weighted imaging of the proband showing no iron deposition in the basal ganglia. (D) Electropherogram of a heterozygous CP c.2158C>T (p. Arg720Trp) mutation of the proband and his father. (E) Electropherogram of a heterozygous PRKCG c.431-457del (p. Arg144Asp153delinsHis) mutation of the proband and his father.

GO TO SECTION 3 


\section{Section 3}

Aceruloplasminemia is a rare autosomal recessive disorder characterized by diabetes, retinal degeneration, and neurodegenerative manifestations caused by biallelic mutation of $C P$, leading to an absence of serum ceruloplasmin and subsequent iron accumulation in the brain, liver, and pancreas. ${ }^{2}$ Previous studies have reported that patients with hypoceruloplasminemia caused by heterozygous mutation of $C P$ can present with neurologic symptoms-mostly cerebellar and extrapyramidal signs-with normal serum ferritin and the absence of diabetes or retinal degeneration. ${ }^{3-5}$ Among these cases, a 16-year-old girl presenting with ataxia, involuntary movement of the right leg, and reduced ceruloplasmin level (100 mg/L) carried the same heterozygous mutation as our patient ${ }^{4}$; her father was asymptomatic, but he exhibited a decreased ceruloplasmin level $(130 \mathrm{mg} / \mathrm{L})$ and carried the same mutation. ${ }^{4}$

Given that our patient's father carried the same heterozygous mutation in $C P$, we tested his father's serum ceruloplasmin level and found it to be decreased $(189 \mathrm{mg} / \mathrm{L})$. The father's level of serum ferritin and glycated hemoglobin were normal. Further neurologic examination of the father revealed abnormal neurologic signs that had not been noticed before, including moderate cerebellar dysarthria, limb and trunk ataxia, and an ataxic gait. His brain MRI showed moderate atrophy of the cerebellum (figure, B).

\section{Questions for consideration:}

1. Can the diagnosis of hypoceruloplasminemia be made?

2. What would you consider next? 


\section{Section 4}

Although heterozygous mutation of $C P$ is reported in several cases to cause symptoms, the association remains controversial. A total of 10 articles have reported hypoceruloplasminemia in 26 individuals with heterozygous mutations of $C P$. Of these cases, only 6 presented with neurologic symptoms (e.g., cerebellar and extrapyramidal signs). ${ }^{5}$ Prior cases have included $A T P 7 B$ screening in addition to $C P$ to exclude the diagnosis of $\mathrm{WD} .{ }^{4}$ Another case study reported a father and his son who presented with slowly progressive cerebellar ataxia and a decreased ceruloplasmin level. A heterozygous mutation of $C P$ (c.2630 G>A, p. Trp858ter) was detected, and a diagnosis of hypoceruloplasminemia was rendered after excluding SCA1, SCA2, SCA3, SCA6, SCA7, SCA8, SCA12, and dentatorubralpallidoluysian atrophy with short tandem repeat (STR) analysis. ${ }^{3}$ However, the possibility of a concomitant SCA caused by non-STR could not be excluded.

Because our patient's father also had ataxic symptoms, we screened with STR analysis for SCAs but did not find any abnormal expansions. To further evaluate whether our patient and his father had causative mutations in other genes, whole exome sequencing (WES) was performed and a heterozygous mutation (c.431-457del, p. Arg144Asp153delinsHis) in exon 5 of the protein kinase $\mathrm{C}$ gamma gene (PRKCG) was detected (figure, E), indicating a diagnosis of SCA14. The mutation was not found in the 1,000 Genomes Project or the Human Genetic Variation Database and was considered to be likely pathogenic according to criteria of the Standards and Guidelines for the Interpretation of Sequence Variant.

\section{Discussion}

SCA14 is a rare, relatively benign phenotype of SCA characterized by slowly progressive ataxia caused by mutation of the PRKCG gene. It accounts for less than $1 \%$ of autosomal dominant cerebellar ataxia. As reported here, the proband's father was not even aware of any ataxic symptoms until neurologic examination was prompted by evaluating his son. In addition to ataxia, other symptoms such as dystonia, tremor, myokymia, and myoclonus have also been observed in patients with SCA14. ${ }^{6}$ Among these symptoms, dystonia is among the most common and could even be the predominant symptom present in SCA14.

Our patient presented with a dystonia-ataxia syndrome, had decreased ceruloplasmin level, and was observed to possess a heterozygous mutation in both $C P$ and PRKCG gene. Although previous articles have suggested that heterozygous mutations of $C P$ can cause cerebellar ataxia in patients with hypoceruloplasminemia, ${ }^{5}$ we noticed that a portion of these patients did not receive a comprehensive workup to exclude other causes of genetic ataxias.,
Dystonia has been reported in many types of SCAs, suggesting a potential common pathogenesis of ataxia and dystonia. Moreover, PRKCG is mainly expressed in the Purkinje cells of the cerebellum, ${ }^{6}$ which have been implicated in dystonia. We therefore considered the mutation of $P R K C G$ to have induced this patient's dystonia-ataxia symptoms. No patient with SCA14 has been reported to exhibit decreased ceruloplasmin level. By using quantitative MRI technology, we previously found that a carrier of a heterozygous $C P$ mutation was asymptomatic despite an excess of iron accumulation detected in the brain. ${ }^{7} \mathrm{We}$ ascribed the decreased ceruloplasmin level to the heterozygous $C P$ mutation, which we suspect is a variance of unknown significance for dystonia-ataxia symptoms.

The findings gleaned from our patient suggest that previous reports of symptomatic hypoceruloplasminemia that has been ascribed to heterozygous mutations of $C P$ may have additional genetic factors that were not discovered, especially in those with a positive family history. Hence, thorough genetic studies are needed in these patients. As shown in our case, the strategy of choice for genetic testing is also important; it should combine WES and STR analyses, since WES cannot detect repeat expansion. We recommend that unless WES is performed or other disorders are rigorously excluded, novel genotype-phenotype correlations that expand the clinical spectrum of a disorder should be made with caution.

Although current treatments for SCAs lack efficacy, ${ }^{8}$ preclinical studies have supported the use of gene modification therapy, such as antisense nucleotide therapy for SCA1, SCA2, and SCA $3 .{ }^{8}$ Data gleaned from positive genetic testing results will benefit the clinical management of patients carrying genetic mutations and inform the development of therapies for treating these symptoms.

The pathogenesis of dystonic tremor remains unknown. A systematic review ${ }^{9}$ recommended botulinum toxin as the firstline treatment for axial (head/vocal cord) dystonic tremor, followed by anticholinergics, clonazepam, and anticonvulsants. Our patient declined botulinum toxin treatment and responded poorly to benzhexol hydrochloride, clonazepam, and baclofen treatment. Topiramate was administered, and remarkable improvement was observed. This was also observed in a previous case study ${ }^{10}$ where the effect of topiramate on dystonic tremor may have been attributable to its effect on GABA activation.

\section{Study funding}

Supported by 1.3.5 Project for Disciplines of Excellence, West China Hospital, Sichuan University (ZYJC18038).

\section{Disclosure}

The authors report no disclosures relevant to the manuscript. Go to Neurology.org/ $\mathrm{N}$ for full disclosures. 


\section{Appendix Authors}

\begin{tabular}{|c|c|c|}
\hline Name & Location & Contribution \\
\hline $\begin{array}{l}\text { Junyu } \\
\text { Lin, MD }\end{array}$ & $\begin{array}{l}\text { West China Hospital, Sichuan } \\
\text { University, Chengdu, China }\end{array}$ & $\begin{array}{l}\text { Drafted and revised the } \\
\text { manuscript, analyzed and } \\
\text { interpreted data }\end{array}$ \\
\hline $\begin{array}{l}\text { Bi Zhao, } \\
\text { MD }\end{array}$ & $\begin{array}{l}\text { West China Hospital, Sichuan } \\
\text { University, Chengdu, China }\end{array}$ & $\begin{array}{l}\text { Analyzed and interpreted } \\
\text { data }\end{array}$ \\
\hline $\begin{array}{l}\text { Bei Cao, } \\
\text { MD }\end{array}$ & $\begin{array}{l}\text { West China Hospital, Sichuan } \\
\text { University, Chengdu, China }\end{array}$ & $\begin{array}{l}\text { Performed critical revision } \\
\text { of the manuscript for } \\
\text { intellectual content }\end{array}$ \\
\hline $\begin{array}{l}\text { Xiaoqin } \\
\text { Yuan, MD }\end{array}$ & $\begin{array}{l}\text { West China Hospital, Sichuan } \\
\text { University, Chengdu, China }\end{array}$ & Revised the manuscript \\
\hline $\begin{array}{l}\text { Xiaojing } \\
\text { Gu, MD }\end{array}$ & $\begin{array}{l}\text { West China Hospital, Sichuan } \\
\text { University, Chengdu, China }\end{array}$ & $\begin{array}{l}\text { Analyzed and interpreted } \\
\text { data }\end{array}$ \\
\hline $\begin{array}{l}\text { Huifang } \\
\text { Shang, } \\
\text { MD }\end{array}$ & $\begin{array}{l}\text { West China Hospital, Sichuan } \\
\text { University, Chengdu, China }\end{array}$ & $\begin{array}{l}\text { Revised the manuscript and } \\
\text { approved all final changes }\end{array}$ \\
\hline
\end{tabular}

\section{References}

1. Rossi M, Balint B, Millar Vernetti P, Bhatia KP, Merello M. Genetic dystonia-ataxia syndromes: clinical spectrum, diagnostic approach, and treatment options. Mov Disord Clin Pract 2018;5:373-382.

2. Harris ZL, Klomp LW, Gitlin JD. Aceruloplasminemia: an inherited neurodegenerative disease with impairment of iron homeostasis. Am J Clin Nutr 1998;67(5 suppl):972S-977S.

3. Miyajima H, Kono S, Takahashi Y, Sugimoto M, Sakamoto M, Sakai N. Cerebellar ataxia associated with heteroallelic ceruloplasmin gene mutation. Neurology 2001;57: 2205-2210.

4. Kuhn J, Miyajima H, Takahashi Y, et al. Extrapyramidal and cerebellar movement disorder in association with heterozygous ceruloplasmin gene mutation. J Neurol 2005;252:111-113.

5. Borges MD, de Albuquerque DM, Lanaro C, Costa FF, Fertrin KY. Clinical relevance of heterozygosis for aceruloplasminemia. Am J Med Genet B Neuropsychiatr Genet 2019;180:266-271.

6. Chelban V, Wiethoff S, Fabian-Jessing BK, et al. Genotype-phenotype correlations, dystonia and disease progression in spinocerebellar ataxia type 14. Mov Disord 2018; 33:1119-1129.

7. Chen $\mathrm{Q}, \mathrm{Chen} \mathrm{XP}$, Zou L, et al. High brain iron level in asymptomatic carriers of heterozygous ceruloplasmin gene mutations. Mov Disord 2008;23:916-917.

8. Ashizawa T, Öz G, Paulson HL. Spinocerebellar ataxias: prospects and challenges for therapy development. Nat Rev Neurol 2018;14:590-605.

9. Fasano A, Bove F, Lang AE. The treatment of dystonic tremor: a systematic review. J Neurol Neurosurg Psychiatry 2014;85:759-769.

10. Papapetropoulos S, Singer C. Improvement of cervico-trunco-brachial segmental dystonia with topiramate. J Neurol 2006;253:535-536. 


\section{Neurology}

\section{Clinical Reasoning: A 24-year-old man with head tremor and decreased ceruloplasmin level}

Junyu Lin, Bi Zhao, Bei Cao, et al.

Neurology 2020;95;e1906-e1910 Published Online before print August 4, 2020

DOI 10.1212/WNL.0000000000010458

This information is current as of August 4, 2020

\section{Updated Information \&} Services

\section{References}

Subspecialty Collections

Permissions \& Licensing

Reprints including high resolution figures, can be found at: http://n.neurology.org/content/95/13/e1906.full

This article cites 10 articles, 3 of which you can access for free at: http://n.neurology.org/content/95/13/e1906.full\#ref-list-1

This article, along with others on similar topics, appears in the following collection(s):

\section{Cerebellum}

http://n.neurology.org/cgi/collection/cerebellum

Dystonia

http://n.neurology.org/cgi/collection/dystonia

Spinocerebellar ataxia

http://n.neurology.org/cgi/collection/spinocerebellar_ataxia

Tremor

http://n.neurology.org/cgi/collection/tremor

Information about reproducing this article in parts (figures,tables) or in its entirety can be found online at:

http://www.neurology.org/about/about_the_journal\#permissions

Information about ordering reprints can be found online:

http://n.neurology.org/subscribers/advertise

Neurology ${ }^{\circledR}$ is the official journal of the American Academy of Neurology. Published continuously since 1951, it is now a weekly with 48 issues per year. Copyright (C 2020 American Academy of Neurology. All rights reserved. Print ISSN: 0028-3878. Online ISSN: 1526-632X.

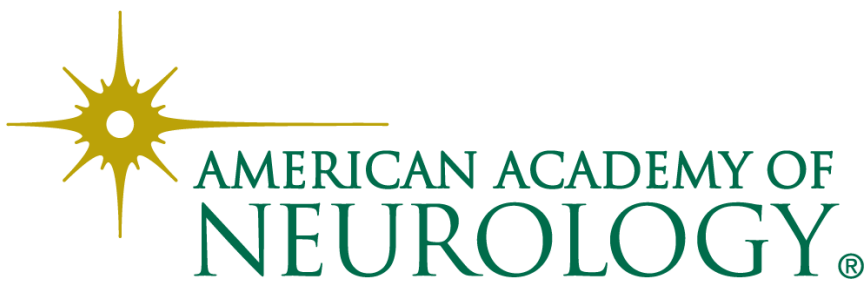

